\title{
Theoretical Description of Mixed Film Formation at the Air/Water Interface: Carboxylic Acids-Fatty Amines
}

\author{
Elena S. Kartashynska, ${ }^{\dagger}+$ Yuri B. Vysotsky, ${ }^{\S}$ Dieter Vollhardt, ${ }^{*}, \|_{\odot}$ Valentin B. Fainerman, ${ }^{\perp}$ \\ and Anatoly Yu. Zakharov \\ ${ }^{\dagger}$ L.M. Litvinenko Institute of Physical Organic and Coal Chemistry, 70 R. Luxemburg Str., Donetsk 83114, Ukraine \\ ${ }^{\ddagger}$ Yaroslav-the-Wise Novgorod State University, 41, B. S.-Peterburgskaya Str., Veliky Novgorod 173003, Russia \\ ${ }^{\S}$ Donetsk National Technical University, 58 Artema Str., Donetsk 83000, Ukraine \\ "Max Planck Institute of Colloids and Interfaces, Potsdam/Golm D-14424, Germany \\ ${ }^{\perp}$ SINTERFACE Technologies, Berlin D-12489, Germany
}

Supporting Information

ABSTRACT: Thermodynamic parameters of mixed monolayer formation of aliphatic amines $\mathrm{C}_{n} \mathrm{H}_{2 n+1} \mathrm{NH}_{2}$ and carboxylic acids $\mathrm{C}_{n} \mathrm{H}_{2 n+1} \mathrm{COOH}(n=6-16)$ are calculated using the quantum chemical semiempirical PM3 method. Four types of mixed dimers and tetramers amine-acid are considered. The total contribution of interactions between the hydrophilic parts of amine and acid into clusterization Gibbs energy is slightly lower than the corresponding interactions for individual surfactants. It suggests a synergetic interaction between the regarded amphiphilic compounds as proved by experimental data in the literature. Two types of competitive film formation are possible: mixed 2D film 1, where the molecules of the minor component are single distributed among the molecules

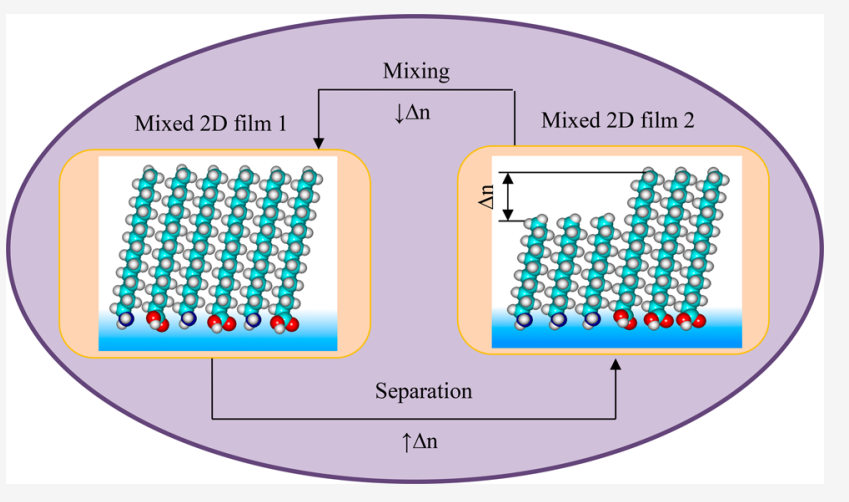
of the prevailing second component (mixture of components on molecular level), and 2D film 2 with a domain structure comprised of pure component "islands" linked together. The dependence of the Gibbs energy of clusterization per monomer for $2 \mathrm{D}$ film 1 on the component mole fraction shows that the maximum synergetic effect is typical for the case that both surfactants have the same even number of carbon atoms in the hydrocarbon chain and form an equimolar mixture. Formation of $2 \mathrm{D}$ film 1 is more preferable than that of $2 \mathrm{D}$ film 2 , if the difference of the hydrocarbon chain lengths is not larger than 5 methylene units. The limiting mole fraction of carboxylic acids in such mixed monolayers is $66.7 \%$.

\section{INTRODUCTION}

Investigation of monomolecular films containing several components is of interest because they can serve as a model system for different physicochemical processes in membranes, for example. ${ }^{1}$ Construction of mixed mono- and multimolecular layers with predefined properties demands the accounting of possible interactions appearing between the homo- and heteromolecules of the amphiphiles present in the mixture. Furthermore, different components do not always mix completely, leading to additional phase separation in mixed Langmuir-Blodgett films. ${ }^{2}$ The characteristics and peculiarities of mixed monolayers of nonionic surfactants, such as amines and carboxylic acids ${ }^{3,4}$ as well as carboxylic acids and fatty alcohols, ${ }^{5}$ should be mentioned. Approaches for the description of intermolecular interactions appearing between amphiphilic molecules in monolayers at the water surface are reviewed in ref 6 . As a rule, mixed monolayers exhibit nonideal behavior at the expense of interactions between the hydrophilic parts of dissimilar surfactants in the system. ${ }^{7-10}$
The existing experimental studies dealing with the behavior of carboxylic acids and amines ${ }^{9-12}$ show that such systems exhibit essential deviations of the mixture parameters from linear dependence. This suggests a high miscibility and nonideal behavior of the components in the mixture. The authors of the study ${ }^{10}$ suppose that mixed monolayers in the system octadecylamine-octadecanoic acid are formed by means of electrostatic forces, which appear between two molecules with oppositely charged hydrophilic parts generated due to an "acid-base" interaction. Some experimental studies ${ }^{4,11}$ conclude that the structure of mixed stearic acid/ octadecylamine monolayers depends on the initial conditions in the experiment. In the case of premixing the individual components, the formed monolayer consists of molecularly mixed structures, whereas otherwise the films are like

Received: November 18, 2019

Revised: December 19, 2019

Published: December 19, 2019 
"patchwork blankets" comprised of "islands" of individual components.

Fewer theoretical papers have been devoted to the behavior simulation of individual surfactants and their mixtures during film formation. ${ }^{13,14}$ Previously, we developed an approach to describe 2D clusterization of pure nonionic surfactants (carboxylic acids, ${ }^{15,16}$ amines, ${ }^{17}$ etc.) at the air/water interface in the framework of quantum chemical modeling (PM3). In addition, this approach has been used to estimate the behavior of carboxylic acids and aliphatic alcohols in the mixed monolayers. ${ }^{18}$ Good agreement between the obtained calculated and experimental results encouraged us to spread the used scheme to the case of carboxylic acids and amines. This study aims at (1) calculation of thermodynamic parameters of mixed clusterization of aliphatic amines $\mathrm{C}_{n} \mathrm{H}_{2 n+1} \mathrm{NH}_{2}$ and carboxylic acids $\mathrm{C}_{n} \mathrm{H}_{2 n+1} \mathrm{COOH}$ with $n=$ 6-16 methylene units in the chain at the air/water interface at standard conditions; and (2) defining the conditions for miscibility of the components on the molecular level or domain formation of the individual components.

\section{METHOD OF CALCULATION}

The quantum chemical program package Mopac $2000^{19}$ (semiempirical PM3 method) is used to calculate the thermodynamic parameters of mixed film formation of aliphatic amines and carboxylic acids at the air/water interface. The calculation method is selected because it is parametrized within the formation heats ${ }^{20,21}$ and adequately describes experimental data concerning the film formation for different classes of individual nonionic surfactants ${ }^{15-17}$ and mixtures of carboxylic acids and alcohols. ${ }^{18}$

Calculation of the thermodynamic parameters of formation and clusterization for associates of carboxylic acids and amines is done using the quantum chemical model described in detail elsewhere. ${ }^{22}$ Here, we just briefly point to some peculiarities of this model. The developed model includes implicit account of the interface impact via its orienting and stretching effect on the surfactant molecules. The water phase retracts the surfactant functional group and possibly several methylene units adjoined to it, whereas the hydrophobic part is repelled into the air phase. Thus, the amphiphilic molecule possesses the most stretched "linear" conformation. So, the model regards the crystalline phase of the monolayer, when the surfactant molecules are densely packed in a "mattress"-like structure floating on the water. Quantum chemical calculation is carried out in supermolecular approximation only for a definite number of surfactant aggregates structurized in some way. Because of the pair additivity of interactions, it is possible to calculate the parameters only for small aggregates (dimers, trimers, and tetramers). The values of their thermodynamic parameters of formation and clusterization depend essentially on the spatial orientation of the monomers in the aggregates. As a result, the values of the clusterization thermodynamic parameters for large and infinite clusters (2D films) can be described using the additive scheme. It represents the required parameters as a sum of contributions of the corresponding $\mathrm{CH} \cdots \mathrm{HC}$ interactions between the surfactant hydrocarbon chains and interactions between the functional groups. Adequacy of the used scheme is supported by numerous comparisons of calculated and experimental data for 11 classes of nonionic surfactants. ${ }^{23}$

\section{RESULTS AND DISCUSSION}

Monomers. We performed the conformation analysis of monomers for aliphatic amines and acids in our previous papers. ${ }^{15-17}$ Three stable conformations are found for amines with the next values of the amine dihedral angle $\angle \mathrm{C}_{2}-\mathrm{C}_{1}-\mathrm{N}-$ $\mathrm{H}_{1}=60^{\circ}, 180^{\circ}$, and $300^{\circ}$ (see Figure 1a). The last conformer

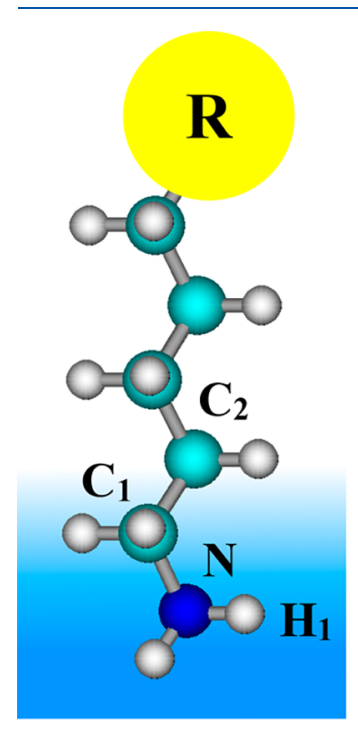

a

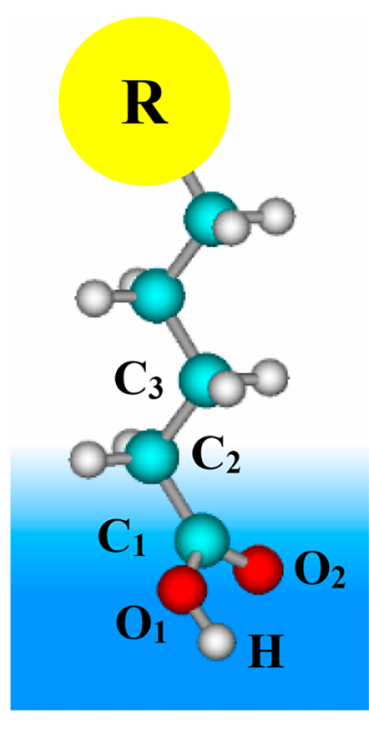

b
Figure 1. Optimized geometries of amine (a) and acid (b) monomers ( $\mathrm{R}$ is a hydrocarbon chain).

is a mirror image of the first one. Conformer 1 is stabilized by hydrogen-hydrogen interactions between the $\alpha$-hydrogen atoms of the hydrocarbon chain and one of the hydrogens of the $\mathrm{NH}_{2}$-group, but the second conformer is stabilized by the interaction of two $\beta$-hydrogen atoms of the hydrocarbon chain with two hydrogen atoms of the amino group. Conformation analysis carried out in the same study ${ }^{17}$ for dimers comprised of both monomer conformations shows that the most stable dimers are built using conformer 1 . Thus, we used this monomer structure for further studies.

Some papers ${ }^{15,16}$ deal with the thermodynamics of the film formation for carboxylic acids. They show that the most energetically favorable acid conformation is a structure with dihedral angles of the functional groups $\angle \mathrm{C}_{2}-\mathrm{C}_{1}-\mathrm{O}_{1}-\mathrm{H}=$ $180^{\circ}$ and $\angle \mathrm{C}_{3}-\mathrm{C}_{2}-\mathrm{C}_{1}-\mathrm{O}_{2}=-78^{\circ}$ (see Figure $1 \mathrm{~b}$ ). According to the conclusions of the experimental study, ${ }^{24}$ the surfactant molecules are in the maximum extended "linear" conformation in the crystalline monolayer. Such monomer structures are used to build mixed amine-acid dimer and tetramer structures.

The calculated values of formation $\Delta H, S^{0}$, and $\Delta G$ for monomers of carboxylic acids and amines agree well with the corresponding experimental data. ${ }^{25}$ They are listed in our previous papers. ${ }^{15-17}$ The calculated data are used to build the correlations between the thermodynamic parameters of the monomer formation and the surfactant chain length $(n)$. The values of the regression coefficients in the equations of type $y=$ $(a \pm \Delta a) \cdot n+(b \pm \Delta b)$ are for enthalpy in $\mathrm{kJ} / \mathrm{mol}, a=-22.68$ and $-22.67, b=-399.47$ and -199.92 for carboxylic acids and amines, respectively; for absolute entropy in $\mathrm{J} /(\mathrm{mol} \cdot \mathrm{K}), a=$ 31.57 and 33.18, $b=267.24$ and 201.74; and for Gibbs energy 
in $\mathrm{kJ} / \mathrm{mol}, a=6.56$ and $7.95, b=-377.66$ and -190.59 . The corresponding correlation coefficients exceed 0.9999 .

Small Clusters. Here, we regard mixed dimers and tetramers of amines and carboxylic acids, which after enlargement form mixed monolayers without domains of individual surfactants, but with single distribution of one component among another. The fragment of such mixed monolayer is shown in Figure 2 for the extreme case when

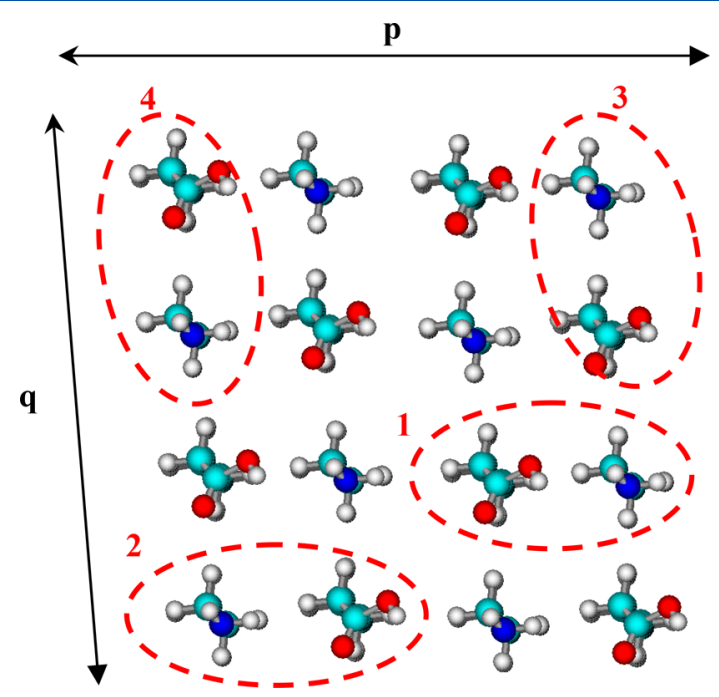

Figure 2. Fragment of geometric structure of mixed 2D film of amines and carboxylic acids $(1: 1)$. The basic dimers are 1 , dimer $1, \mathrm{p} ; 2$, dimer 2 ,p; 3, dimer $1, \mathrm{~s}$; and 4 , dimer 2 ,s.

amines and acids are taken in a 1:1 ratio. However, it is also possible to form monolayers when one component prevails to the other. In such a case, it is worthwhile to regard also pure surfactant dimers and tetramers. So, four types of mixed dimers can be singled out: in two directions of two each and two types of pure dimers for both individual components.

Geometry optimization is completed for four series of mixed dimers possessing the same hydrocarbon chain length for both amines and carboxylic acids $(n=6-16)$. However, it is possible to obtain mixed films with compounds of different chain length. Our previous study ${ }^{26}$ about the inclusion of alkane molecules into alcohol monolayers shows that accounting for the mixed aggregate structures with all possible chain lengths does not affect the values of the contributions of intermolecular $\mathrm{CH} \cdots \mathrm{HC}$ interactions into the thermodynamic parameters of formation and clusterization. So, we set a limit and calculated only four types of dimers with equal number of $\mathrm{CH}_{2}$-fragments in the hydrocarbon chain.

Figure 3 lists the optimized structures of the considered dimers using associates with 12 methylene units in the chain. Note that the mixed dimer 1,p has quite a weak hydrogen bond between one of the hydrogen atoms of the amino group and the hydroxylic oxygen of the acid. In the mixed dimer 2 ,s, the hydrogen bond is absent. In the mixed dimer $1, \mathrm{~s}$, hydrogen bonding between the carbonyl oxygen of the acid $\mathrm{COOH}$ group and the hydrogen of the $\mathrm{NH}_{2}$-group is extremely weak. It should be also noted that the mixed dimer $1, \mathrm{p}$ possesses a distorted value of the dihedral angle $\angle \mathrm{C}_{3}-\mathrm{C}_{2}-\mathrm{C}_{1}-\mathrm{O}_{2}\left(-118^{\circ}\right.$ instead of $\left.-78^{\circ}\right)$. This leads to formation of a hydrogen bond between the carbonyl oxygen of the acid $\mathrm{COOH}$-group and the hydrogen of the $\mathrm{NH}_{2}$-group. However, the mixed tetramers of square structure and larger clusters do not have such "edge effects". So, the series of such dimers does not participate in further construction of the general correlation. The required values of contributions for the hydrophilic headgroup interactions are singled out with help of the mixed tetramers of the square structure.

Thermodynamic parameters of formation and clusterization are calculated for all small aggregate structures described above. Clusterization enthalpy, entropy, and Gibbs energy are calculated as follows: $\Delta H_{298, \mathrm{~m}}^{\mathrm{Cl}}=\Delta H_{298}^{0}-d \cdot \Delta H_{298, \operatorname{mon}\left(\mathrm{NH}_{2}\right)^{0}-}$ $f \cdot \Delta H_{298, \operatorname{mon}(\mathrm{COOH})}^{0} \quad \Delta S_{298, \mathrm{~m}}^{\mathrm{Cl}}=S_{298}^{0}-d \cdot S_{298, \operatorname{mon}\left(\mathrm{NH}_{2}\right)^{0}}-f$. $S_{298, \operatorname{mon}(\mathrm{COOH}) ;}^{0} \Delta G_{298, \mathrm{~m}}^{\mathrm{Cl}}=\Delta H_{298, \mathrm{~m}}^{\mathrm{Cl}}-T \cdot \Delta S_{298, \mathrm{~m}}^{\mathrm{Cl}}$, where $\Delta H_{298}^{0}$ and $S_{298}^{0}$ are the variations of formation enthalpy and absolute entropy for the corresponding associates at $298 \mathrm{~K}$;

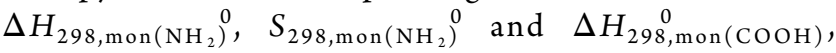
$S_{298 \text {,mon }(\mathrm{COOH})}^{0}$ are the variations of formation enthalpy and absolute entropy for monomers of amines and carboxylic acids, respectively, at $298 \mathrm{~K} ; m$ is the total number of surfactant molecules in the regarded cluster; and $d$ and $f$ are the numbers of amine and acid molecules in the regarded cluster, respectively. The calculated thermodynamic parameters of dimerization for pure and mixed dimers are listed in Table S1.

The results of the direct calculations show that formation of pure amine dimers is possible for compounds with 16 and more carbon atoms in the hydrocarbon chain and for acids with $18 \mathrm{CH}_{2}$ units. This threshold is 16 methylene units for the mixed dimers. The partial correlation dependences of the thermodynamic dimerization parameters on the surfactant chain length are built for all types of pure and mixed dimers. Regression parameters are summarized in Table S2. Here, we only mention that the contribution of one $\mathrm{CH} \cdots \mathrm{HC}$ interaction into dimerization enthalpy varies within the limit of $-(10.22-10.32) \mathrm{kJ} / \mathrm{mol}$. Accounting for the calculation error, we find that these deviations are statistically insignificant. This makes it possible to unite the partial correlations into the general one. In addition, these values almost coincide with the corresponding contributions of pure dimers and tetramers of amines and carboxylic acids. In case of entropy, the contribution of one $\mathrm{CH} \cdots \mathrm{HC}$ interaction makes - $(21.77-$ 26.94) $\mathrm{J} /(\mathrm{mol} \cdot \mathrm{K})$ that also virtually coincides with the corresponding values for pure dimers and tetramers of individual compounds. For the dimerization Gibbs energy, the contribution of one $\mathrm{CH} \cdots \mathrm{HC}$ interaction varies from -2.24 to $-2.86 \mathrm{~kJ} / \mathrm{mol}$. For mixed tetramers, it makes $-3.84 \mathrm{~kJ} / \mathrm{mol}$. The contribution of the functional groups to the dimerization enthalpy turns to be statistically insignificant except for the mixed dimer 1,s as well as for dimers of the individual compounds except for the dimer $\mathrm{NH}_{2}$, p. The contribution of the head groups into the dimerization entropy is almost the same for all mixed dimers within the calculation error.

As in previous studies, ${ }^{16,27}$ the partial correlations are united into a general one for mixed and pure dimers to single out the contributions of intermolecular $\mathrm{CH} \cdots \mathrm{HC}$ interactions and interactions of the functional groups as well:

$$
\begin{aligned}
& \Delta H_{298}^{\operatorname{dim}}=-(10.30 \pm 0.06) \cdot K_{\mathrm{a}}-(2.35 \pm 0.71) \cdot n_{\mathrm{NH}_{2}, \mathrm{p}} \\
& \quad-(0.97 \pm 0.47) \cdot\left(n_{1, \mathrm{p}}+n_{2, \mathrm{~s}}+n_{\mathrm{COOH}, \mathrm{s}}\right) \\
& \quad-(3.79 \pm 0.67) \cdot n_{1, \mathrm{~s}} \\
& {[N=88 ; R=0.9997 ; S=2.31 \mathrm{~kJ} / \mathrm{mol}]}
\end{aligned}
$$



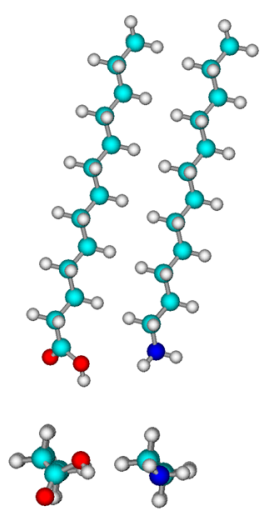

Mixed Dimer 1,p
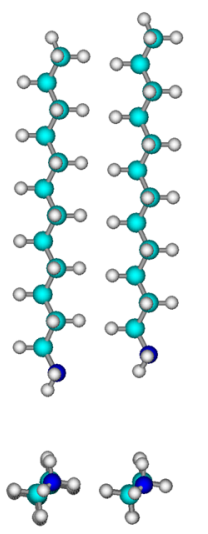

Dimer $\mathrm{NH}_{2}, \mathrm{p}$
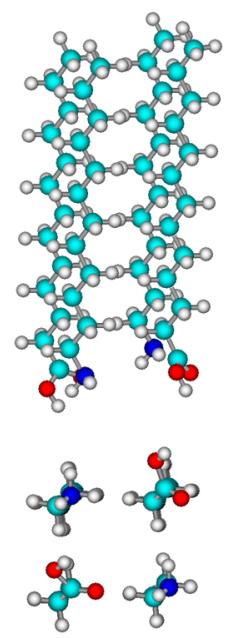

Mixed Tetramer
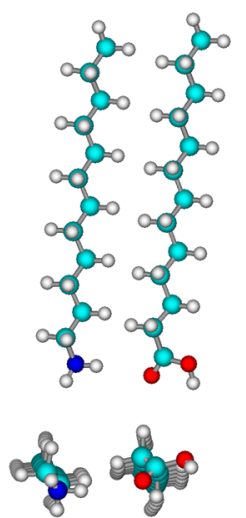

Mixed Dimer 2,p

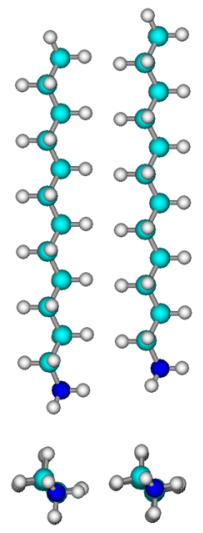

Dimer $\mathrm{NH}_{2}, \mathrm{~s}$

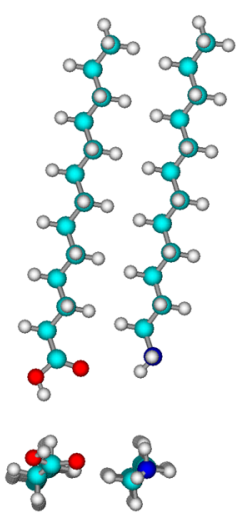

Mixed Dimer 1,s
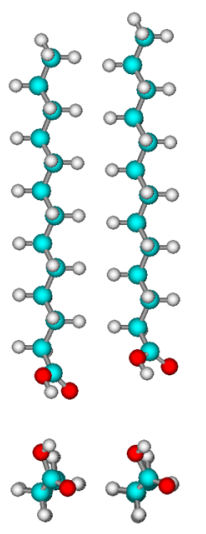

Dimer COOH,p
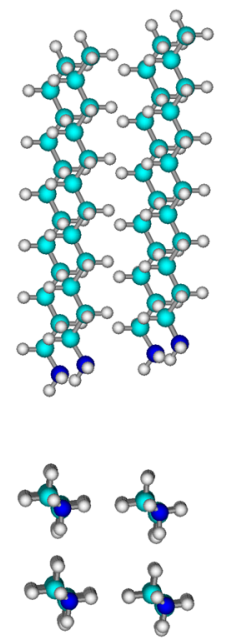

Tetramer $\mathrm{NH}_{2}$

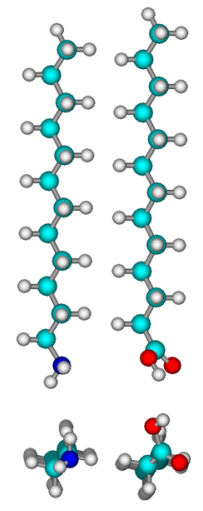

Mixed Dimer 2,s

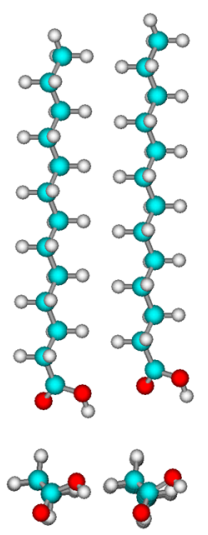

Dimer $\mathrm{COOH}, \mathrm{s}$
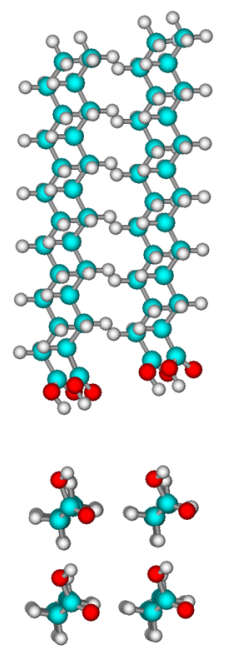

Tetramer $\mathrm{COOH}$

Figure 3. Optimized geometric structures of mixed and pure aggregates of amines and carboxylic acids with $n=12$ methylene units in the chain.

$$
\begin{aligned}
& \Delta S_{298}^{\operatorname{dim}}=-(22.55 \pm 0.35) \cdot K_{\mathrm{a}}-(94.73 \pm 2.73) \cdot \\
& \quad\left(n_{\mathrm{NH}_{2, \mathrm{p}}}+n_{\mathrm{NH}_{2, \mathrm{~s}}}\right)-(99.74 \pm 2.45) \cdot\left(n_{1, \mathrm{p}}+n_{1, \mathrm{~s}}+n_{2, \mathrm{~s}}\right) \\
& \quad-(108.05 \pm 3.39) \cdot n_{\mathrm{COOH}, \mathrm{p}}-(117.94 \pm 3.39) \cdot n_{\mathrm{COOH}, \mathrm{s}} \\
& \quad[N=88 ; R=0.9997 ; S=9.42 \mathrm{~J} /(\mathrm{mol} \cdot \mathrm{K})]
\end{aligned}
$$

$$
\begin{aligned}
& \Delta G_{298}^{\operatorname{dim}}=-(3.53 \pm 0.06) \cdot K_{\mathrm{a}}+(28.02 \pm 0.45) \cdot \\
& \quad\left(n_{1, \mathrm{p}}+n_{2, \mathrm{~s}}+n_{\mathrm{NH}_{2, \mathrm{~s}}}\right)+(26.26 \pm 0.50) \cdot\left(n_{1, \mathrm{~s}}+n_{\mathrm{NH}_{2, \mathrm{p}}}\right) \\
& \quad+(31.51 \pm 0.60) \cdot n_{\mathrm{COOH}, \mathrm{p}}+(33.80 \pm 0.60) \cdot n_{\mathrm{COOH}, \mathrm{s}} \\
& {[N=88 ; R=0.9932 ; S=1.69 \mathrm{~kJ} / \mathrm{mol}]}
\end{aligned}
$$


where $K_{\mathrm{a}}$ is the number of intermolecular $\mathrm{CH} \cdots \mathrm{HC}$ interactions present in the regarded dimer; it is defined as

for pure dimers:

$$
K_{\mathrm{a}}=\left\{\frac{n_{\mathrm{COOH}}}{2}\right\} \text { or } K_{\mathrm{a}}=\left\{\frac{n_{\mathrm{NH}_{2}}}{2}\right\}
$$

depending on the number of $\mathrm{CH}_{2}$ units in the surfactant chain $(n)$ in both directions of the spread monolayer

and for mixed dimers:

$$
K_{\mathrm{a}}=\min \left[\left\{\frac{n_{\mathrm{COOH}}+1}{2}\right\} ;\left\{\frac{n_{\mathrm{NH}_{2}}}{2}\right\}\right]
$$

where the braces denote the integer part of the number; and $n_{1, \mathrm{p}}, n_{2, \mathrm{p}}, n_{1, \mathrm{~s}}, n_{2, \mathrm{~s}}$ and $n_{\mathrm{NH}_{2}, \mathrm{p}}, n_{\mathrm{NH}_{2}, \mathrm{~s}}, n_{\mathrm{COOH}, \mathrm{p}}, n_{\mathrm{COOH}, \mathrm{s}}$ are the identifiers of the functional group interactions for amines and carboxylic acids in the structures of mixed and pure associates. If $n_{1, \mathrm{p}}=1$, such interaction is present in the regarded aggregate. If the value of the corresponding identifier is equal to zero, then it is absent. The value of the corresponding identifier is equal to the number of such interactions in the considered cluster.

In the following, we give a detailed account of the case when the hydrocarbon chain lengths of amines and acids are not the same, and how it affects the number of $\mathrm{CH} \cdots \mathrm{HC}$ interactions in the mixed dimer. If the chain length $n_{\mathrm{COOH}}=10$ (undecanoic acid) and $n_{\mathrm{NH}_{2}}=6$ or 7 , three $\mathrm{CH} \cdots \mathrm{HC}$ interactions are realized in such a dimer. With lengthening of the amine chain length to $n_{\mathrm{NH}_{2}}=8$ or 9 , four $\mathrm{CH} \cdots \mathrm{HC}$ interactions are achieved in the mixed dimer with the same acid. Elongation of the amine chain length by two additional methylene units leads to the maximum possible number of five $\mathrm{CH} \cdots \mathrm{HC}$ interactions for mixed dimers with the same acid. Further lengthening of the amine chain with constant acid length does not affect the number of $\mathrm{CH} \cdots \mathrm{HC}$ interactions realized in the dimers. So, the maximum possible number of such interactions is defined by the short-chained compound in the pair. Before the maximum value, the number of $\mathrm{CH} \cdot \cdots \mathrm{HC}$ interactions depends stepwise on the surfactant with the shorter hydrocarbon chain length.

Figure 4 illustrates the graphs of dependences of dimerization Gibbs energy for pure and mixed amine-acid structures on the surfactant chain length for the case when $n_{\mathrm{NH}_{2}}$ $=n_{\mathrm{COOH}}$. Here, the lines correspond to the dependences obtained using eqs $1-3$, but the dots are the results of the direct calculations. The dependences of dimerization parameters for pure amines and acids calculated earlier ${ }^{16,17}$ are also shown here for comparison. The data of the direct calculations using the PM3 method are in good agreement with the predicted values. It is clear that dimer 2,p is energetically most favorable among all four types of mixed dimers. Formation of such dimers is even more advantageous than for pure dimers. The other three dimer types differ slightly from each other within dimerization energy and are almost isoenergetic with the corresponding dimers for pure amines. This allows the suggestion that during mixed clusterization amines and acids will form monolayers comprised of pairs amine-acid, when amine molecules contact acid ones but not the ones of the same class. ${ }^{5,12}$ However, it should be noted that it is possible to get mixed films with so-called domain structure obtained by contact of "islands" of the individual surfactants. In the

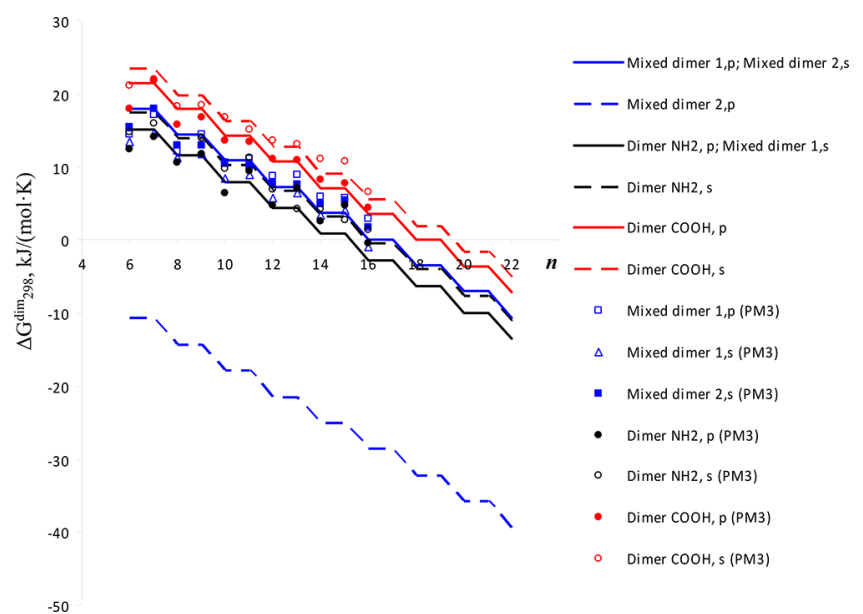

Figure 4. Dependence of dimerization Gibbs energy on the number of methylene units in the surfactant hydrocarbon chains.

experimental study, ${ }^{11}$ it is stated that formation of mixed monolayer with one or another structure depends on the experimental methodology, notably, the stage of preliminary mixing of components in the solvent before spreading on the water surface.

All partial correlations for the regarded associates are generalized to obtain the additive scheme:

$$
\begin{aligned}
& {[N=106 ; R=0.9998 ; S=2.81 \mathrm{~kJ} / \mathrm{mol}]} \\
& {[N=106 ; R=0.9990 ; S=20.17 \mathrm{~J} /(\mathrm{mol} \cdot \mathrm{K})]} \\
& {[N=106 ; R=0.9683 ; S=3.36 \mathrm{~kJ} / \mathrm{mol}]}
\end{aligned}
$$

where the parameters $K_{\mathrm{a}}, n_{1, \mathrm{p}}, n_{2, \mathrm{p}}, n_{1, \mathrm{~s}}$, and $n_{2, \mathrm{~s}}$ have the same meaning as in eqs $1-5$.

Large and Infinite Clusters. As in our previous study, ${ }^{18}$ here we consider two possible types of mixed films: monolayer with miscibility of components on the molecular level (2D film 1) and monolayer comprised of individual domains attached to each other (2D film 2).

2D Films 1 with Single Distribution of Minor Component in the Other. In such monolayers, the molecules of the minor component are not placed together, but completely surrounded by the molecules of the prevalent component. Define the interactions realized between the hydrophilic parts of the same surfactant as $n_{\mathrm{NH}_{2}, \mathrm{p}}$ and $n_{\mathrm{NH}_{2}, \mathrm{~s}}$ for amines and $n_{\mathrm{COOH}, \mathrm{p}}$ and $n_{\mathrm{COOH}, \mathrm{q}}$ for carboxylic acids. In the extreme case when the mixture is equimolar, the monolayer consists of dimers amine-acid as shown in Figure 2. Except for $\mathrm{CH} \cdot \cdots \mathrm{HC}$ interactions realized between surfactant hydrocarbon chains, the monolayers possess interactions realized between hydrophilic parts of amine and carboxylic acid as in dimers 1,p and $2, \mathrm{p}$ in the $p$-direction of the spread monolayer and dimers $1, \mathrm{~s}$ and $2, \mathrm{~s}$ in the $q$-direction. The numbers of these interactions are defined as $n_{1, \mathrm{p}}, n_{2, \mathrm{p}}$ and $n_{1, \mathrm{~s}}, n_{2, \mathrm{~s}}$, respectively.

The numbers of interactions described above can be expressed as

$$
\begin{aligned}
& n_{1, \mathrm{p}}=n_{2, \mathrm{p}}=n_{1, \mathrm{~s}}=n_{2, \mathrm{~s}}=0.5 X \cdot p q ; n_{\mathrm{NH}_{2} / \mathrm{COOH}, \mathrm{p}} \\
& \quad=q(p-1)-2 X \cdot p q ; n_{\mathrm{NH}_{2} / \mathrm{COOH}, \mathrm{s}}=p(q-1) \\
& -2 X \cdot p q
\end{aligned}
$$


regardless of the arrangement of acid molecules in the amine monolayer and vice versa.

Here, $X$ is the molar fraction of the minor component; and $p$ and $q$ are the numbers of molecules forming the cluster in the corresponding direction.

The number of $\mathrm{CH} \cdots \mathrm{HC}$ interactions depends on the acid $n_{\mathrm{COOH}}$ and amine $n_{\mathrm{NH}_{2}}$ hydrocarbon chain as follows:

$$
\begin{aligned}
& K_{\mathrm{a}}=[(q(p-1)-2 X \cdot p q)+(p(q-1)-2 X \cdot p q)] \cdot \\
& \quad\left\{\frac{n_{\mathrm{NH}_{2} / \mathrm{COOH}}}{2}\right\}+4 X \cdot p q \cdot \min \left[\left\{\frac{n_{\mathrm{COOH}}+1}{2}\right\} ;\left\{\frac{n_{\mathrm{NH}_{2}}}{2}\right\}\right]
\end{aligned}
$$

where the integer part of the number is denoted with braces.

We should obtain the expressions for calculation of clusterization thermodynamic parameters per one monomer molecule of the 2D film. Let us use the standard approach for such a goal: the dependences 9 and 10 should be divided by the total number of monomers in the cluster $(m=p \cdot q)$, and then the limits of these expressions should be calculated when $m$ tends to infinity. For the mixed 2D film $(p=\infty, q=\infty)$, the dependences 9 and 10 transform into:

$$
\begin{aligned}
& n_{1, \mathrm{p}}^{\infty} / m=n_{2, \mathrm{p}}^{\infty} / m=n_{1, \mathrm{~s}}^{\infty} / m=n_{2, \mathrm{~s}}^{\infty} / m=X ; n_{\mathrm{NH}_{2} / \mathrm{COOH}, \mathrm{p}}^{\infty} / m \\
& \quad=n_{\mathrm{NH}_{2} / \mathrm{COOH}, \mathrm{s}}^{\infty} / m=1-2 X
\end{aligned}
$$

The number of $\mathrm{CH} \cdots \mathrm{HC}$ interactions per one molecule of the film can be calculated as follows:

$$
\begin{aligned}
& K_{\mathrm{a}}^{\infty} / m=2 \cdot\left((1-2 X) \cdot\left\{\frac{n_{\mathrm{COOH} / \mathrm{NH}_{2}}}{2}\right\}\right. \\
& \left.+2 X \cdot \min \left[\left\{\frac{n_{\mathrm{COOH}}+1}{2}\right\} ;\left\{\frac{n_{\mathrm{NH}_{2}}}{2}\right\}\right]\right)
\end{aligned}
$$

where $X, n_{\mathrm{COOH}}$, and $n_{\mathrm{NH}_{2}}$ have the same meaning as in expressions 9 and 10 .

Using eqs 10 and 11 , we get the expressions for calculation of $\Delta H_{298}^{\mathrm{Cl}, \infty} / \mathrm{m}, \Delta S_{298}^{\mathrm{Cl}, \infty} / \mathrm{m}$, and $\Delta G_{298}^{\mathrm{Cl}, \infty} / \mathrm{m}$ of mixed infinite 2D films depending on the hydrocarbon chain length of surfactants and the mixture content. There are two possible cases. The expressions for the films with acid molar fraction $X_{\mathrm{COOH}}<0.5$ are

$$
\begin{aligned}
& \Delta H_{298}^{\mathrm{Cl}, \infty} / m=-10.39 \cdot K_{\mathrm{a}}^{\infty} / m+6.33 \cdot X_{\mathrm{COOH}}-4.96 \\
& \Delta S_{298}^{\mathrm{Cl}, \infty} / m=-22.69 \cdot K_{\mathrm{a}}^{\infty} / m+35.72 \cdot X_{\mathrm{COOH}}-165.97 \\
& \Delta G_{298}^{\mathrm{Cl}, \infty} / m=-3.63 \cdot K_{\mathrm{a}}^{\infty} / m-4.31 \cdot X_{\mathrm{COOH}}+44.50
\end{aligned}
$$

For the second case when the acid molar fraction exceeds 0.5 , the expressions for $\Delta H_{298}^{\mathrm{Cl}, \infty} / m, \Delta S_{298}^{\mathrm{Cl}, \infty} / m$, and $\Delta G_{298}^{\mathrm{Cl}, \infty} / m$ become:

$$
\begin{aligned}
& \Delta H_{298}^{\mathrm{Cl}, \infty} / m=-10.39 \cdot K_{\mathrm{a}}^{\infty} / m-3.59 \cdot X_{\mathrm{NH}_{2}} \\
& \Delta S_{298}^{\mathrm{Cl}, \infty} / m=-22.69 \cdot K_{\mathrm{a}}^{\infty} / m+23.65 \cdot X_{\mathrm{NH}_{2}}-159.96 \\
& \Delta G_{298}^{\mathrm{Cl}, \infty} / m=-3.63 \cdot K_{\mathrm{a}}^{\infty} / m-10.65 \cdot X_{\mathrm{NH}_{2}}+47.67
\end{aligned}
$$

Here, $K_{\mathrm{a}}^{\infty} / m$ is the number of intermolecular $\mathrm{CH} \cdots \mathrm{HC}$ interactions per one surfactant molecule in the mixed $2 \mathrm{D}$ film (see eq 12).
Note that the mixed interactions amine-carboxylic acid contribute less in total than the corresponding interactions of the individual surfactants into the clusterization Gibbs energy. This leads to preferable formation of $2 \mathrm{D}$ films 1 with miscibility of components on molecular level.

Figure 5 illustrates the graphical dependences of $\Delta G_{298}^{\mathrm{Cl}, \infty} / \mathrm{m}$ obtained using eq 15 for carboxylic acid content $10 \mathrm{~mol} \%$ in

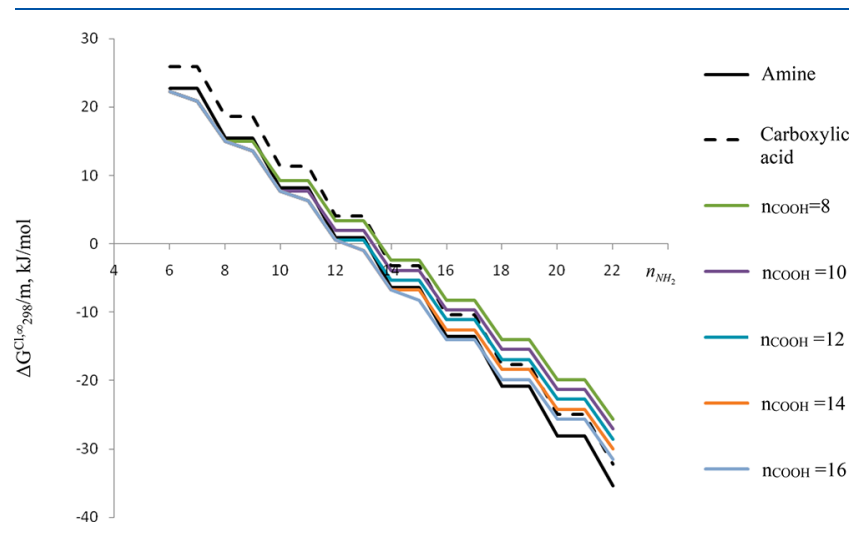

Figure 5. Dependence of $\Delta G_{298}^{\mathrm{Cl}, \infty} / m$ variation for mixed 2D films 1 on the number of methylene units in the amine and acids chain $\left(X_{\mathrm{COOH}}\right.$ $=10 \mathrm{~mol} \%$ ).

the monolayer. The black solid line defines film formation for pure amines, but the dotted one defines for pure carboxylic acids. The color lines correspond to the formation of mixed monolayers at definite acid chain length and variation of amine chain length from 6 to 22 methylene units. It is seen that shortening of the acid chain length introduced into the amine monolayer leads to less preference of such film comparatively to the one with a longer-chained acid. This is caused by the effect already described above by the example of the amineacid dimers. If the chain lengths for these compounds are not equal, then the less number of $\mathrm{CH} \cdots \mathrm{HC}$ interactions realized is comparative to the maximum possible value for the longer compound. At the same time, a somewhat bigger preference of amine-acid interactions does not exceed the lack of the contribution from the lost $\mathrm{CH} \cdots \mathrm{HC}$ interactions.

Now we consider in detail how the mixture content affects the preference of the monolayer formation for surfactants with the same hydrocarbon chain length. Figure 6 shows that the dependences for clusterization Gbbs energy of mixed films are

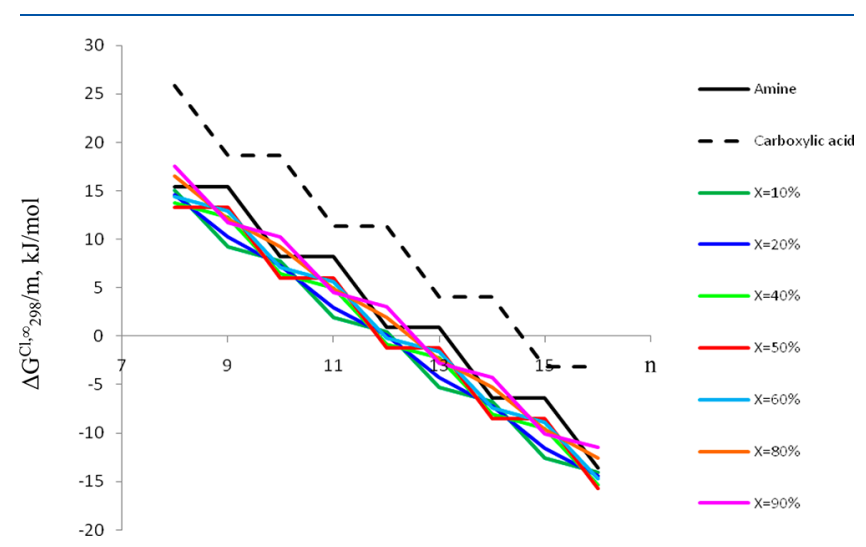

Figure 6. Dependence of $\Delta G_{298}^{\mathrm{Cl}, \infty} / m$ variation for mixed 2D films 1 on the carboxylic acid molar fraction $X$ ( $n$ is the number of carbon atoms in the surfactant alkyl chain). 
lower than the corresponding dependences for the individual components (except for the cases with $X_{\mathrm{COOH}}=80$ and $90 \mathrm{~mol}$ $\%)$. This indicates a synergetic interaction between amine and acid hydrophilic parts unlike in the case considered in our previous study devoted to mixtures of aliphatic alcohols and carboxylic acids. ${ }^{18}$ In the last case, dependences of $\Delta G_{298}^{\mathrm{Cl}, \infty} / \mathrm{m}$ for mixed alcohol-acid films are between the lines of the corresponding dependences for pure monolayers. This indicates the absence of synergetic action between alcohol and acid molecules. This results in ideal behavior of their mixtures during monolayer formation. The maximum synergetic effect for amine and acid mixtures appears when both compounds are in an equimolar ratio and possess an even number of carbon atoms in the chain. In this case, mixed films have the same number of $\mathrm{CH} \cdots \mathrm{HC}$ interactions as in the monolayers of the pure components. This results in ideal behavior of their mixtures during the monolayer formation. The maximum synergetic effect for amine and acid mixtures appears when both compounds are in an equimolar ratio and possess an even number of carbon atoms in the chain. In this case, mixed films have the same number of $\mathrm{CH} \cdots \mathrm{HC}$ interactions as in monolayers of pure components. In addition, a slightly better energetic contribution of mixed interactions than for the corresponding homointeractions results in the maximal advantage of just that very case for equimolar mixed films.

The obtained calculated results agree well with the existing experimental data concerning $\Pi-\mathrm{A}$ isotherms for pure and mixed monolayers of octadecylamine and octadecanoic acid. $^{4,11}$ In these papers, Lee and coauthors regard two possible types of mixed film formation. If the individual components are premixed in solvent before spreading on the water surface, mixed 2D films on molecular level are obtained; otherwise, films with domain structure are obtained. In the films of the first type, the essential deviations from the linear law are registered for dependences of area per molecule and $A_{\text {ex }} / A_{\text {id }}\left(A_{\text {ex }}\right.$ is an excess area per molecule, while $A_{\text {id }}$ is the area per molecule in an ideal mixture) on the acid molar fraction. This indicates a special interaction between dissimilar components. The results of Brewster angle microscopy (BAM) for such monolayers indicate their high rigidity. The studies ${ }^{8,9}$ reveal that the films with miscibility of components on molecular level are most stable if the amine-acid ratio is 1:1. The advantage of amine-acid interactions can be stipulated by several reasons. As the regarded surfactants belong to acid and base classes, it enables the neutralization reaction with salt formation. ${ }^{12}$ It is also possible that two hydrophilic parts of the regarded surfactants ionize and adsorb together with "catanionic surfactant" formation. ${ }^{10,28,29}$

2D Films 2 with Domain Structure. We consider the calculation of thermodynamic clusterization parameters for $2 \mathrm{D}$ films 2 in detail to assess how acid and amine molecules structurize in the mixed monolayers. Such films are like "patchwork blankets", where the surfactants of the same class form "islands" surrounded by the "islands" of the second component. As in our previous study, ${ }^{18}$ now we should account for the interactions between the hydrophilic parts of dissimilar surfactants. Yet, the number of such interactions tends to zero during the transition to thermodynamic parameter per one molecule of the film. So, these parameters $A_{298}^{\mathrm{Cl}, \infty, \mathrm{dom}} / \mathrm{m}$ can be presented as the weighted mean value of the corresponding parameters for monolayers of the pure components: amine $A_{298}^{\mathrm{Cl}, \infty, \mathrm{NH}_{2}} / m$ and carboxylic acid
$A_{298}^{\mathrm{Cl}, \infty, \mathrm{COOH}} / m$. That is, $A_{298}^{\mathrm{Cl}, \infty, \mathrm{dom}} / m=X \cdot A_{298}^{\mathrm{Cl}, \infty, \mathrm{COOH}} / m+(1-$ $X) \cdot A_{298}^{\mathrm{Cl}, \infty, \mathrm{NH}_{2}} / m$, where $X$ is the molar fraction of carboxylic acid in the mixed monolayer. The interactions of the amine hydrophilic parts contribute $-4.96 \mathrm{~kJ} / \mathrm{mol}$ in clusterization enthalpy, $-165.97 \mathrm{~J} /(\mathrm{mol} \cdot \mathrm{K})$ in entropy, and $44.50 \mathrm{~kJ} / \mathrm{mol}$ in Gibbs energy. For carboxylic acids, these contributions are $-159.96 \mathrm{~J} /(\mathrm{mol} \cdot \mathrm{K})$ and $47.67 \mathrm{~kJ} / \mathrm{mol}$ for entropy and Gibbs energy, respectively, whereas for clusterization enthalpy, such a contribution is statistically insignificant. For the mixed amineacid 2D films 2, the expressions for calculation of $\Delta H_{298}^{\mathrm{Cl}, \infty} / \mathrm{m}$, $\Delta S_{298}^{\mathrm{Cl}, \infty} / m$, and $\Delta G_{298}^{\mathrm{Cl}, \infty} / m$ are as follows:

$$
\begin{aligned}
& \Delta H_{298}^{\mathrm{Cl}, \infty, \mathrm{dom}} / m=-10.39 \cdot K_{\mathrm{a}}^{\infty} / m+4.96 \cdot X-4.96 \\
& \Delta S_{298}^{\mathrm{Cl}, \infty, \mathrm{dom}} / m=-22.69 \cdot K_{\mathrm{a}}^{\infty} / m+6.01 \cdot X-165.97 \\
& \Delta G_{298}^{\mathrm{Cl}, \infty, \mathrm{dom}} / m=-3.63 \cdot K_{\mathrm{a}}^{\infty} / m+3.17 \cdot X+44.50
\end{aligned}
$$

where $X$ is the acid molar fraction; and $K_{\mathrm{a}}^{\infty} / m$ is the number of intermolecular $\mathrm{CH} \cdots \mathrm{HC}$ interactions per one molecule of the 2D film, which depends on the number of $\mathrm{CH}_{2}$ units in the hydrocarbon chain $(n)$ as $2 \cdot\left\{\frac{n}{2}\right\}$.

As seen from eq 21 , it transforms into formulas $\Delta G_{298}^{\mathrm{Cl}, \infty, \mathrm{COOH}} / m$ and $\Delta G_{298}^{\mathrm{Cl}, \infty, \mathrm{NH}_{2}} / m$ for calculation of pure acid or amine monolayers in extreme cases for acid molar fraction equal to 1 or 0 . For other mixture contents, the corresponding characteristics will have the values limited to extreme ones for pure compounds and possess linear dependence on the molar fraction of the regarded component. This conforms to the results of experimental investigations ${ }^{4,11}$ for mixed monolayers of octadecylamine and octadecanoic acid obtained without premixing before spreading on the water surface. The area per molecule in such monolayers depends almost linearly on the component molar fraction, and the ratio $A_{\text {ex }} / A_{\text {id }}$ does not exceed $3 \%$. This suggests the absence or extremely small miscibility of the components in the monolayer.

The obtained clusterization Gibbs energy dependences for the mixed films of two types allow one to reveal the surfactant chain length for preferable formation of one of them. The thermodynamic condition written below defines the preferable formation of a mixed monolayer with single distribution of one component in the other comparatively to one with the domain structure:

$$
\Delta \Delta G_{298}^{\mathrm{Cl}, \infty} / m=\left[\Delta G_{298}^{\mathrm{Cl}, \infty} / m-\Delta G_{298}^{\mathrm{Cl}, \infty, \mathrm{dom}} / m\right] \leq 0
$$

The value of $\Delta G_{298}^{\mathrm{Cl}, \infty} / m$ for $2 \mathrm{D}$ film 1 can be generally expressed as follows:

$$
\begin{aligned}
& \Delta G_{298}^{\mathrm{Cl}, \infty} / m=U \cdot K_{\mathrm{a}}^{\infty} / m+(1-2 X) \cdot V^{\mathrm{NH}_{2}}+2 X \cdot A \\
& \quad \text { at } X<0.5 \\
& \Delta G_{298}^{\mathrm{Cl}, \infty} / m=U \cdot K_{\mathrm{a}}^{\infty} / m+(1-2 X) \cdot V^{\mathrm{COOH}} \\
& \quad+2(1-X) \cdot A \text { at } X>0.5
\end{aligned}
$$

where $X$ is the molar fraction of acids in the amine monolayer; $K_{\mathrm{a}}^{\infty} / m$ is the number of intermolecular $\mathrm{CH} \cdots \mathrm{HC}$ interactions per surfactant molecule in the film; $U$ is the value contributed by one $\mathrm{CH} \cdots \mathrm{HC}$ interaction to the clusterization Gibbs energy $(-3.63 \mathrm{~kJ} / \mathrm{mol}) ; V^{\mathrm{NH}_{2}}$ and $V^{\mathrm{COOH}}$ are the values contributed by the hydrophilic headgroup interactions for individual surfac- 


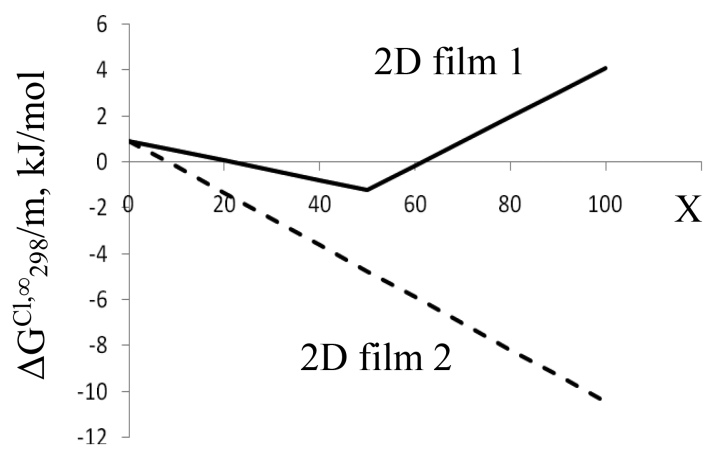

a

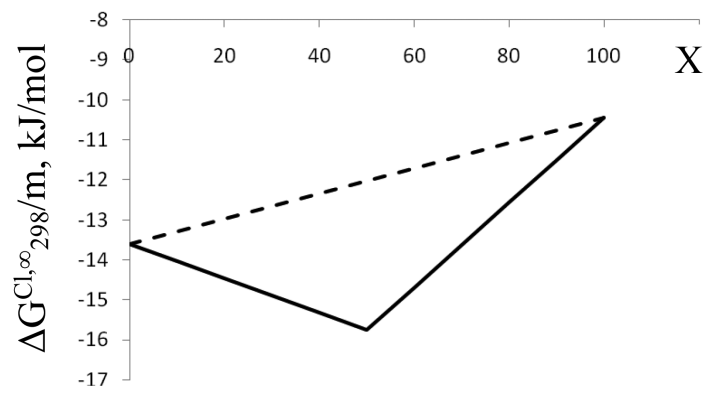

c

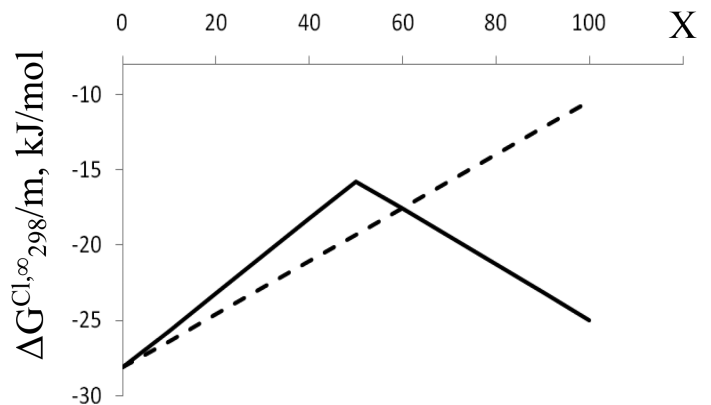

e

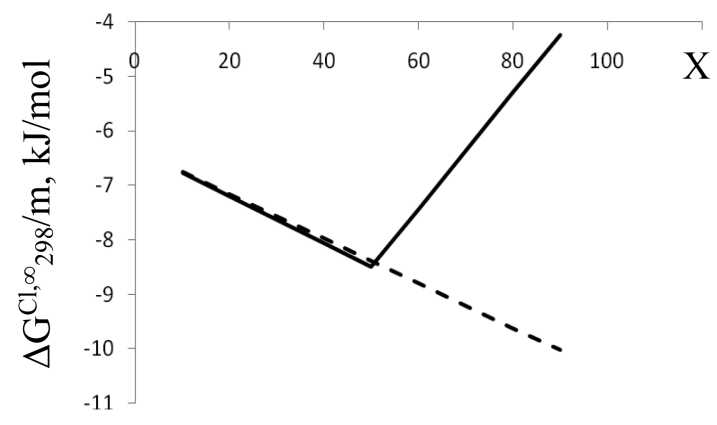

b

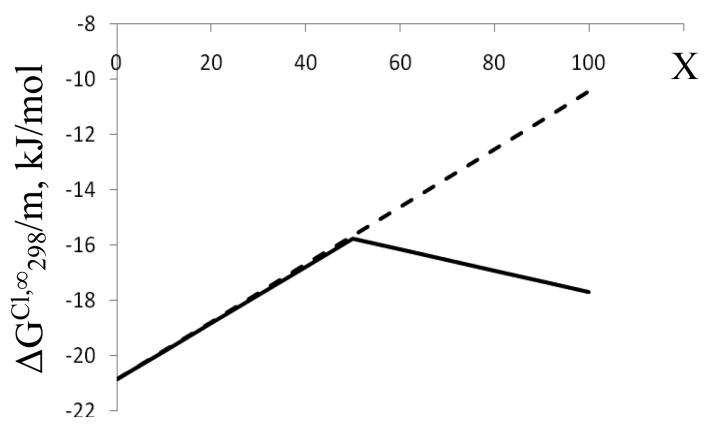

d

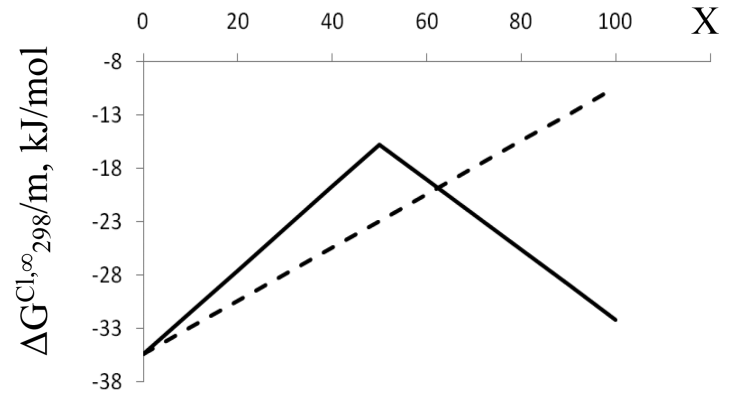

f

Figure 7. Dependence of $\Delta G_{298}^{\mathrm{Cl}, \infty} / m$ on carboxylic acid content in films $(X, \mathrm{~mol} \%)$ at given chain lengths of acid $\left(n_{\mathrm{COOH}}=16\right)$ and amine: $($ a $) n_{\mathrm{NH}}$ $=12$, (b) $n_{\mathrm{NH}_{2}}=14$, (c) $n_{\mathrm{NH}_{2}}=16$, (d) $n_{\mathrm{NH}_{2}}=18$, (e) $n_{\mathrm{NH}_{2}}=20$, and (f) $n_{\mathrm{NH}_{2}}=22$.

tants: 44.50 and $47.67 \mathrm{~kJ} / \mathrm{mol}$ for amines and acids, respectively; and $A$ is the value contributed by the hydrophilic "head" interactions in mixed pairs amine-carboxylic acid $(42.34 \mathrm{~kJ} / \mathrm{mol})$.

For 2D films 2 with domain structure, it is possible to write

$$
\begin{aligned}
\Delta G_{298}^{\mathrm{Cl}, \infty, \mathrm{dom}} / m= & U \cdot K_{\mathrm{a}}^{\infty} / m+V^{\mathrm{NH}_{2}} \\
& +X \cdot\left(V^{\mathrm{NH}_{2}}-V^{\mathrm{COOH}}\right)
\end{aligned}
$$

Using eqs 23-25, mentioned above, it is easy to then obtain the expression for $\Delta \Delta G_{298, \infty}^{\mathrm{Cl}} / m$ :

$$
\begin{aligned}
\Delta \Delta & G_{298, \infty}^{\mathrm{Cl}} / m=\left[U \cdot \Delta K_{\mathrm{a}}^{\infty} / m-X \cdot\left(V^{\mathrm{NH}_{2}}+V^{\mathrm{COOH}}\right)\right. \\
+ & 2 \cdot A \cdot X] \leq 0
\end{aligned}
$$

where $X$ is the molar fraction of acids in the amine monolayer; and $\Delta K_{\mathrm{a}}^{\infty} / m$ is the number of intermolecular $\mathrm{CH} \cdots \mathrm{HC}$ interactions per surfactant molecule in the film lost because of the difference in the hydrocarbon chain lengths of amines and acids.

The value of $\Delta K_{\mathrm{a}}^{\infty} / m$ depends on the hydrocarbon chain length and molar fraction of the corresponding surfactants in the film (see eq 12). It can be expressed as

$$
\Delta K_{\mathrm{a}}^{\infty} / m=4 X \cdot\left(\min \left[\left\{\frac{n_{\mathrm{COOH}}+1}{2}\right\} ;\left\{\frac{n_{\mathrm{NH}_{2}}}{2}\right\}\right]-\left\{\frac{n_{\mathrm{NH}_{2}}}{2}\right\}\right)
$$

where $n_{\mathrm{NH}_{2}}$ and $n_{\mathrm{OH}}$ are the numbers of the methylene units in amine and carboxylic acid chains, respectively; and the braces denotes the integer part of the number.

After several transformations, the inequality 26 turns into the following one:

$$
\left|\left\{\frac{n_{\mathrm{COOH}}+1}{2}\right\}-\left\{\frac{n_{\mathrm{NH}_{2}}}{2}\right\}\right| \leq \frac{V^{\mathrm{NH}_{2}}+V^{\mathrm{COOH}}-2 A}{4 U}
$$


After substituting into eq 28 all values of the corresponding interactions, and after rounding the obtained value to the following bigger integer number, we get the value $\frac{V^{\mathrm{NH}_{2}}+V^{\mathrm{COOH}}-2 A}{4 U}$ is equal to 1 . It should be taken into account that if the surfactants possess an equal number of $\mathrm{CH}_{2}$ units in the chain, then the difference $\left\{\frac{n_{\mathrm{COOH}}+1}{2}\right\}-\left\{\frac{n_{\mathrm{NH}_{2}}}{2}\right\}$ can be 0 or 1 (for even and odd values of $n$ ). So, the absolute value of this difference should exceed 1 or 2 . Taking the value $\left\{\frac{n_{\mathrm{COOH}}+1}{2}\right\}-\left\{\frac{n_{\mathrm{NH}_{2}}}{2}\right\}$ modulo is stipulated by the fact that both components can be longer or shorter than each other in the mixed monolayer. In total, formation of the mixed films with single distribution of surfactant among the molecules of the other component is favorable, if the difference of the surfactant chain lengths does not exceed 5 methylene units. For example, 2D film 1 preferentially forms for pentadecanoic acid $\left(n_{\mathrm{COOH}}=14\right.$ methylene units not including the carbon of the carboxylic group) and amines with $n_{\mathrm{NH}_{2}}=12-17$.

It is also interesting to determine the regions of mixture contents with preferable formation of $2 \mathrm{D}$ film 1 for surfactants with different chains lengths satisfying the condition described above. $\Delta G_{298}^{\mathrm{Cl}, \infty} / m$ of $2 \mathrm{D}$ film 1 can be expressed as follows:

$$
\begin{aligned}
& \Delta G_{298}^{\mathrm{Cl}, \infty} / m=\Delta G_{298}^{\mathrm{Cl}, \infty, \mathrm{NH}_{2}} / m-2 U \cdot \Delta n+2 U \cdot X \cdot \Delta n \\
& +A^{\prime \prime}{ }_{\text {mix }} \cdot X-A_{\text {dom }}^{\prime}+A^{\prime}{ }_{\text {mix }}
\end{aligned}
$$

where $\Delta G_{298}^{\mathrm{Cl}, \infty, \mathrm{NH}_{2}} / m$ is the clusterization Gibbs energy for amine with the given hydrocarbon chain length; $\Delta n$ is the difference of the surfactant chain lengths participating in the film formation; $X$ is the molar fraction of acids in the amine monolayer; $A_{\text {mix }}^{\prime} A_{\text {mix }}^{\prime \prime}$ and $A_{\text {dom }}^{\prime}$ correspond to the value of the $X$ held constant in eqs 15,18 , and 21 ; and $U$ has the same meaning as in eqs $23-25$.

The expression for $\Delta G_{298}^{\mathrm{Cl}, \infty, \mathrm{dom}} / m$ of $2 \mathrm{D}$ film 2 can be written as

$$
\begin{aligned}
& \Delta G_{298}^{\mathrm{Cl}, \infty, \mathrm{dom}} / m=\Delta G_{298}^{\mathrm{Cl}, \infty, \mathrm{NH}_{2}} / m-U \cdot X \cdot \Delta n \\
& \quad+X \cdot\left(V^{\mathrm{COOH}}-V^{\mathrm{NH}_{2}}\right)
\end{aligned}
$$

where $\Delta G_{298}^{\mathrm{Cl}, \infty, \mathrm{NH}_{2}} / m$ is the clusterization Gibbs energy for amine with given chain length; $\Delta n$ is the difference of the surfactant chain lengths; and $X, U, V^{\mathrm{NH}_{2}}$, and $V^{\mathrm{COOH}}$ have the same meaning as in eqs $23-25$.

Using the above preference condition for formation of the film with a single distribution of the minor component in the other comparatively to the film with domain structure (see formula 22), it is possible to obtain an expression for $X$ corresponding to this condition (given that $A_{\text {dom }}^{\prime}=V^{\mathrm{NH}_{2}}-$ $\left.V^{\mathrm{COOH}}\right)$ :

$$
X \geq \frac{2 U \cdot \Delta n-A^{\prime}{ }_{\text {mix }}+V^{\mathrm{COOH}}-V^{\mathrm{NH}_{2}}}{3 U \cdot \Delta n-A_{\text {mix }}^{\prime}+V^{\mathrm{COOH}}-V^{\mathrm{NH}_{2}}}
$$

The obtained linear-fractional dependence can be illustrated by the example of heptadecanoic acid $\left(n_{\mathrm{COOH}}=16\right.$ methylene fragments in the chain) and amines with a chain length $n_{\mathrm{NH}_{2}}=$ 12-20 methylene fragments. As can be seen in Figure $7 \mathrm{a}$, a change in the film structure occurs during an increase of amine chain length as compared to the selected carboxylic acid. For example, heptadecanoic acid and dodecylamine $\left(n_{\mathrm{NH}_{2}}=12\right.$ methylene fragments in the chain) form mixed films with a domain structure at any ratio of component concentrations (see Figure 7a). When the amine chain is extended by two methylene fragments $n_{\mathrm{NH}_{2}}=14$, the situation is changed. The more preferred formation of $2 \mathrm{D}$ films with a single distribution of carboxylic acid molecules in the amine monolayer will be maintained almost until the equimolar ratio of the components is reached. At higher acid concentrations, the separation of components with the film formation of the domain structure will become more beneficial (see Figure $7 \mathrm{~b}$ ). If the chain length of the amine is extended by two more methylene units (16-17 carbon atoms) and equal to the chain length of the selected carboxylic acid, then the preference for the formation of the structure of $2 \mathrm{D}$ films 1 extends to the entire range of the mixture contents. The same picture will be preserved, if the chain length of amines increases by another two methylene fragments (see Figure $7 \mathrm{c}$ and $\mathrm{d}$ ). A further increase in the difference in the chain lengths of individual compounds will lead to the fact that the preference for the formation of $2 \mathrm{D}$ films 1 will slightly shift to the region of predominance of carboxylic acids in the mixture (see Figure $7 \mathrm{e}$ and f). In the limit, as follows from eq 31 , the content of carboxylic acid can reach $X=66.7 \mathrm{~mol} \%$, when the acid hydrocarbon chain is longer by an infinitely number of methylene fragments $\Delta n$ in comparison with the selected amine.

\section{CONCLUSIONS}

The thermodynamic parameters of mixed clusterization of carboxylic acids $\mathrm{C}_{n} \mathrm{H}_{2 n+1} \mathrm{COOH}$ and aliphatic amines $\mathrm{C}_{n} \mathrm{H}_{2 n+1} \mathrm{NH}_{2} \quad(n=6-16)$ on the air/water interface are calculated within the semiempirical PM3 method. The obtained results allow us to formulate the following conclusions:

(1) Carboxylic acid-amine interactions are synergistic as opposed to carboxylic acid-alcohol interactions, ${ }^{18}$ as is most obvious in equimolar mixtures of components with the same chain length.

(2) Competitive formation of two types of mixed films is possible depending on the surfactant hydrocarbon chain length. Mixed films with a single distribution of the minor component among the molecules of the other (2D film 1) will mainly form, if $\left|\left\{\frac{n_{\mathrm{COOH}}+1}{2}\right\}-\left\{\frac{n_{\mathrm{NH}_{2}}}{2}\right\}\right| \leq 2$, which corresponds to a difference between the hydrocarbon chain length of the surfactants of no more than 5 methylene fragments.

(3) The content of carboxylic acids should not exceed the value $X \leq \frac{7.26 \cdot \Delta n+7.48}{10.89 \cdot \Delta n+7.48}$, which in the limit at $\Delta n \rightarrow \infty$ is 66.7 mol \%.

The obtained results agree with the available experimental data indicating the presence of a more energetically favorable interaction between carboxylic acids and amines, which enables one to obtain stable mixed films of these surfactants. ${ }^{4,9-12}$

\section{ASSOCIATED CONTENT}

\section{S Supporting Information}

The Supporting Information is available free of charge at https://pubs.acs.org/doi/10.1021/acs.jpcc.9b10798.

Standard thermodynamic characteristics of clusterization for pure and mixed aggregates of amines and carboxylic acids calculated within PM3 approximation; and parameters of partial correlation equations for thermo- 
dynamic clusterization characteristics of pure and mixed aggregates (PDF)

\section{AUTHOR INFORMATION}

\section{Corresponding Author}

*E-mail: dieter.vollhardt@mpikg.mpg.de.

ORCID $\odot$

Dieter Vollhardt: 0000-0002-5297-4638

Notes

The authors declare no competing financial interest.

\section{ACKNOWLEDGMENTS}

E.S.K. acknowledges the partial financial support by the Ministry of Education and Science of Russian Federation within the framework of the project part of the state order no. 3.3572.2017. Open Access funding was provided by the Max Planck Society.

\section{REFERENCES}

(1) Li, T.; Lilja, K.; Morris, R. J.; Brandani, G. B. LangmuirBlodgett technique for anisotropic colloids: Young. J. Colloid Interface Sci. 2019, 540, 420-438.

(2) Matsumoto, M.; Tanaka, M.; Azumi, R.; Manda, E.; Tachibana, H.; Kondo, Y.; Yoshino, N. Component Exchange in Phase-Separated LB Films of a Long-Chain Silane-Coupling Agent Mixed with Conventional Amphiphiles. Mol. Cryst. Liq. Cryst. Sci. Technol., Sect. A 1997, 294, 31-34.

(3) Lee, Y.-L.; Yang, Y.-C.; Shen, Y.-J. Monolayer Characteristics of Mixed Octadecylamine and Stearic Acid at the Air/Water Interface. J. Phys. Chem. B 2005, 109, 4662-4667.

(4) Lee, Y.-L.; Liu, K.-L. Relaxation Behaviors of Monolayers of Octadecylamine and Stearic Acid at the Air/Water Interface. Langmuir 2004, 20, 3180-3187.

(5) Matuo, H.; Hiromoto, K.; Matuura, R. Mixed monolayers of long normal chain fatty acids with long normal chain fatty alcohol. Bull. Chem. Soc. Jpn. 1978, 51, 690-693.

(6) Dynarowicz-Łatka, P.; Kita, K. Molecular interaction in mixed monolayers at the air/water interface. Adv. Colloid Interface Sci. 1999, 79, $1-17$.

(7) Costin, I. S.; Barnes, G. T. Two-component monolayers. II. Surface pressure-area relations for the octadecanol-docosyl sulphate system. J. Colloid Interface Sci. 1975, 51, 106-121.

(8) Tah, B.; Pal, P.; Mahato, M.; Talapatra, G. B. Aggregation Behavior of SDS/CTAB Catanionic Surfactant Mixure in Aqueous Solution and at the Air/Water Interface. J. Phys. Chem. B 2011, 115, 8493-8499.

(9) Mutsuzaki, H.; Azumi, R.; Tachibana, H.; Sakai, H.; Abe, M.; Matsumoto, M. Salt Formation in the Langmuir-Blodgett Films of Arachidic Acid Mixed with Amphiphilic Ammonium Ions and an Amphiphilic Amine. Chem. Lett. 1999, 28, 505-506.

(10) Stosch, R.; Cammenga, H. K. Molecular Interactions in Mixed Monolayers of Octadecanoic Acid and Three Related Amphiphiles. J. Colloid Interface Sci. 2000, 230, 291-297.

(11) Lee, Y.-L.; Liu, K.-L. Relaxation Behaviors of Monolayers of Octadecylamine and Stearic Acid at the Air/Water Interface. Langmuir 2004, 20, 3180-3187.

(12) Puggelli, M.; Gabrielli, G.; Caminati, G. Langmuir-Blodgett monolayers and multilayers of stearic acid and stearyl amine. Thin Solid Films 1994, 244, 1050-1054.

(13) Ergin, G.; Lbadaoui-Darvas, M.; Takahama, S. Molecular Structure Inhibiting Synergism in Charged Surfactant Mixtures: An Atomistic Molecular Dynamics Simulation Study. Langmuir 2017, 33, 14093-14104.

(14) Toledano, O.; Gálvez, O. Energetics and structure of Langmuir monolayers of palmitic acid: a DFT study. Phys. Chem. Chem. Phys. 2019, 21, 11203-11213.
(15) Vysotsky, Yu.B.; Muratov, D. V.; Boldyreva, F. L.; Fainerman, V. B.; Vollhardt, D.; Miller, R. Quantum Chemical Analysis of the Thermodynamics of 2D Cluster Formation of n-Carboxylic Acids at the Air/Water Interface. J. Phys. Chem. B 2006, 110, 4717-4730.

(16) Vysotsky, Yu. B.; Belyaeva, E. A.; Fomina, E. S.; Vollhardt, D.; Fainerman, V. B.; Miller, R. The quantum-chemical approach to calculations of thermodynamic and structural parameters of formation of fatty acid monolayers with hexagonal packing at the air/water interface. Phys. Chem. Chem. Phys. 2014, 16, 3187-3199.

(17) Vysotsky, Yu.B.; Belyaeva, E. A.; Fainerman, V. B.; Aksenenko, E. V.; Vollhardt, D.; Miller, R. Quantum Chemical Analysis of the Thermodynamics of 2-Dimensional Cluster Formation of Alkylamines at the Air/Water Interface. J. Phys. Chem. C 2007, 111, 15342-15349.

(18) Kartashynska, E. S.; Vysotsky, Yu. B.; Vollhardt, D.; Fainerman, V. B.; Zakharov, A. Yu. Theoretical Description of Mixed Film Formation at the Air/Water Interface: Carboxylic Acids - Alcohols. ACS Omega 2018, 3, 16693-16705.

(19) Stewart, J. J. MOPAC 2000.00 Manual; Fujitsu Limited: Tokyo, 1999.

(20) Solov'ev, M. E.; Solov'ev, M. M. Komp'yuternaya himiya (in Russian); SOLON-Press: Moscow, 2005.

(21) Stone, A. J. The Theory of Intermolecular Force; Clarendon Press: Oxford, 1996.

(22) Vysotsky, Y. B.; Belyaeva, E. A.; Kartashynska, E. S.; Fainerman, V. B.; Smirnova, N. A. Quantum Chemical Approach in the Description of the Amphiphile Clusterization at the Air/Liquid and Liquid/Liquid Interfaces withPhase Nature Accounting. I. Aliphatic Normal Alcohols at the Air/Water Interface. J. Phys. Chem. B 2015, $119,3281-3296$.

(23) Vysotsky, Yu. B.; Kartashynska, E. S.; Belyaeva, E. A.; Fainerman, V. B.; Vollhardt, D.; Miller, R. Computational Quantum Chemistry Applied to Monolayer Formation at Gas/Liquid Interfaces. In Computational Methods for Complex Liquid-Fluid Interfaces; Karbaschi, M., Miller, R., Rahni, T., Eds.; CRC Press: New York, 2016; pp 199-249.

(24) Knobler, C. M.; Desai, R. C. Phase Transitions in Monolayers. Annu. Rev. Phys. Chem. 1992, 43, 207-236.

(25) Stull, D. R.; Westrum, E. F., Jr.; Sinke, G. C. The Chemical Thermodynamics of Organic Compounds; John Wiley \& Sons: New York, 1969.

(26) Vysotsky, Yu.B.; Fomina, E. S.; Belyaeva, E. A.; Fainerman, V. B.; Vollhardt, D. On the Inclusion of Alkanes into the Monolayer of Aliphatic Alcohols at the Water/Vapor of Alkanes Interface. A Quantum-Chemical Approach. Phys. Chem. Chem. Phys. 2013, 15, 2159-2176.

(27) Fomina, E. S.; Vysotsky, Yu. B.; Belyaeva, E. A.; Vollhardt, D.; Fainerman, V. B.; Miller, R. On Hexagonal Orientation of Fatty Alcohols in Monolayers at the Air/Water Interface: QuantumChemical Approach. J. Phys. Chem. C 2014, 118, 4122-4130.

(28) Gonçalves da Silva, A. M.; Viseu, M. I.; Campos, C. S.; Rechena, T. Effect of the spreading procedure on the formation of cationic-anionic mixed monolayers. Thin Solid Films 1998, 320, 236-240.

(29) Viseu, M. I.; Gonçalves da Silva, A. M.; Costa, S. M. B. Reorganization and Desorption of Catanionic Monolayers. Kinetics of $\pi-t$ and A-t Relaxation. Langmuir 2001, 17, 1529-1537. 